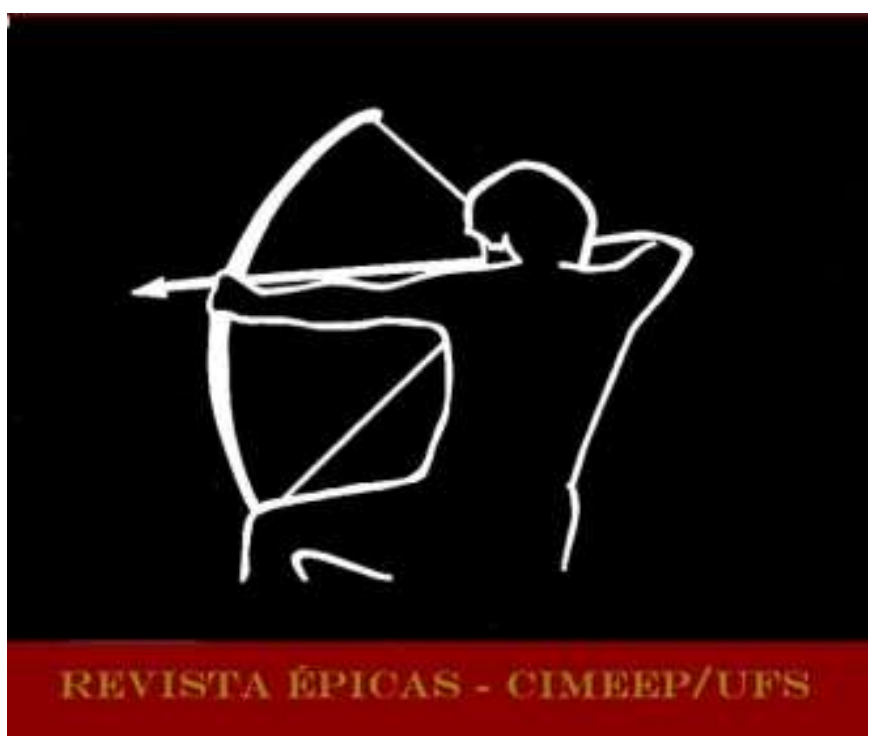

TOFOLI, Barbara Faria; LEITE, Leni Ribeiro. A recepção da ékphrasis no poema épico Prosopopeia, de Bento Teixeira. In: Revista Épicas. Ano 4, N. 8, Dez 2020, p. 187-207. ISSN 2527-080-X. DOI: http://dx.doi.org/10.47044/2527-080X.2020v8.187207

\title{
A RECEPÇÃO DA ÉKPHRASIS NO POEMA ÉPICO PROSOPOPEIA, DE BENTO TEIXEIRA
}

\section{THE RECEPTION OF ÉKPHRASIS IN THE EPIC POEM PROSOPOPEIA, BY BENTO TEIXEIRA}

\author{
Barbara Faria Tofoli ${ }^{1}$ \\ Universidade Federal do Espírito Santo, UFES \\ Leni Ribeiro Leite ${ }^{2}$ \\ Universidade Federal do Espírito Santo, UFES
}

RESUMO: Busca-se compreender diversas acepções atribuídas à êcfrase de forma a analisar seu uso, como recurso linguístico, no poema épico Prosopopeia (1601), de Bento Teixeira, cujo discurso, delineado pela Retórica, serve-se da êcfrase para legitimar ou construir uma argumentação. Diante disso, são apresentadas particularidades acerca da produção letrada da América Portuguesa, para que, então, sejam discutidas questões concernentes à Retórica Antiga e, mais precisamente, à êcfrase. A análise consiste em delimitação e discussão de trechos ecfrásticos presentes no poema, a fim de que a êcfrase seja associada à filiação ao gênero épico e ao caráter retórico dos versos de Bento Teixeira.

Palavras-chave: êcfrase; Retórica Antiga; Recepção dos clássicos; Prosopopeia; Bento Teixeira.

ABSTRACT: We seek to understand the different meanings attributed to ekphrasis in order to analyze its use, as a linguistic resource, in the epic poem Prosopopeia (1601), by Bento Teixeira, whose discourse, outlined by Rhetoric, uses the ekphrasis to legitimize or build an argumentation. In order to do so, particularities about the literate production of Portuguese America are presented, and issues concerning Ancient Rhetoric and, more precisely, the ekphrasis are discussed. The analysis consists of delimitation and discussion of ecfrastic passages present in the

\footnotetext{
1 Mestranda do Programa de Pós-Graduação em Letras da Universidade Federal do Espírito Santo. E-mail: barbarafariat@gmail.com.

2 Professora Associada de Língua e Literatura Latina da Universidade Federal do Espírito Santo. Doutora em Letras Clássicas pela Universidade Federal do Rio de Janeiro (2008) E-mail: leni.ribeiro@gmail.com.
} 
poem, so that the ekphrasis is associated with the affiliation to the epic genre and the rhetorical character of Bento Teixeira's verses.

Keywords: ekphrasis; Ancient Rhetoric; Reception of classics; Prosopopeia; Bento Teixeira.

\section{Introdução}

Poucos são os estudos sobre o que foi produzido no Brasil em seus primeiros séculos frente aos majoritários estudos sobre a literatura brasileira do século XIX em diante (LEITE, 2019, p. 211). A escassez de pesquisas relativas à América Portuguesa facilita a criação de anacronismos sobre as literaturas dos séculos XVI ao XVIII, através de um lugar-comum generalizante em relação às práticas letradas coloniais. Em contraponto, e seguindo a linha de pesquisadores como Hansen (2006a), Sinkevisque (2013) e Santos (2018), pretendemos analisar o poema épico de Bento Teixeira Prosopopeia (1601), considerando que a representação letrada da América Portuguesa se deu em retomada aos ditames da instituição retórica, cuja durabilidade se deu desde o "tempo de Platão e Aristóteles até a revolução romântica na segunda metade do século XVIII" (HANSEN, 2012, p. 159). Lançando o olhar aos estudos sobre Recepção, realizaremos a leitura do poema seiscentista destacando a retomada de uma figura retórica específica, a êcfrase - isto é, uma descrição detalhada e vívida que expõe aos olhos o que é descrito (Theon. Prog. 118-120) -, a partir da noção de que, conciliada à narrativa das proezas de Jorge de Albuquerque Coelho, a quem o poema é dedicado, a êcfrase, como artifício retórico, aproxima os escritos da audiência, de forma a estimular seu páthos ${ }^{3}$, mediante a representação imagética dos elementos da narrativa.

Segundo Bakogianni (2016, p. 115), os estudos da Recepção ${ }^{4}$ determinam que esta se pauta na perspectiva de que não há "texto único, original, objetivo e fixo", mas textos variados interpretados e reinterpretados de maneiras distintas a cada leitura, sendo possível, nesse sentido, verificar como os escritos e os preceitos da Antiguidade Clássica são recuperados e dispostos nas letras modernas. Retomando Martindale, em Redeeming the text (1993), pode-se afirmar que os significados são constituídos e atualizados no ponto de recepção, que, de acordo

\footnotetext{
3 De acordo com Quintiliano (Inst. 6.2.8-10), páthos está associado à emoção, sendo acionado ao estimular uma reação emocional no ouvinte, comovendo-o.

${ }^{4}$ A teoria da Recepção deriva de estudos sobre estética da recepção, como os de Jauss (1982), Iser (1978) e Gadamer (1960), que apresentam o protagonismo do leitor na formulação de significados (BAKOGIANNI, 2016, p. 115), bem como se vinculam aos estudos de Kristeva (1967), sobre intertextualidade, e de Bakhtin (2013, p. 47), a partir do conceito de dialogismo.
} 
com Batstone (2008, p. 17), seria a interface em que texto e leitor se encontram e constituem significados. Sob essa perspectiva, podemos observar que as obras antigas são recebidas na Modernidade de forma a constituir acepções particulares e relevantes ao seu momento histórico. Por isso, as categorias retórico-poéticas antigas são recuperadas nos escritos modernos, em função da comoção patética e da persuasão da audiência em relação à manutenção de uma ordem hierárquica ${ }^{5}$ cujos membros, partes, ordens e funções estão subordinados ao rei, que comanda pelo bem comum (HANSEN, 2006a, p. 39). Inserido nas práticas literárias quinhentistas, Bento Teixeira transpõe elementos da Antiguidade Clássica de maneira significativa ao seu presente, estabelecendo, assim, uma instância de recepção do mundo clássico. Dentre os elementos retrabalhados pelo poeta, está a êcfrase, sendo esta utilizada não somente enquanto procedimento ornamental, conforme compreendido modernamente ${ }^{6}$, mas como importante instrumento argumentativo, como pretendemos demonstrar.

\section{Bento Teixeira e sua produção poética}

Bento Teixeira foi um poeta quinhentista lusófono nascido na cidade do Porto, que, ainda na infância, mudou-se com a família para o Brasil, onde residiu nas capitanias do Espírito Santo, do Rio de Janeiro, da Bahia e de Pernambuco (RIBEIRO, 2012, p. 50-51). Teixeira tinha origem judaica, formou-se no Colégio da Companhia de Jesus e, estando em território colonial como cristão-novo ${ }^{7}$, casou-se com a também cristã Filipa Raposo (RIBEIRO, 2012, p. 51). Quando estudante do Colégio Jesuítico da Bahia, no século XVI, manteve contato com línguas, autores e preceitos antigos e seus estudos foram mediados por valores católicos (SOUZA, 2015, p. 367). Sua

\footnotetext{
${ }^{5}$ A ordem hierárquica prescrita por Portugal e estendida à América Portuguesa se relaciona à noção de "corpo místico". Essa expressão faz menção ao Império português, que se estruturava como um corpo em que o rei representava a cabeça e os súditos, seus membros, sendo estes hierarquicamente dispostos "fosse no Reino fosse na vastidão das áreas coloniais, de forma idealmente harmônica" (PAES, 2006: 163).

${ }^{6}$ A êcfrase, em seu sentido moderno, é compreendida como descrição de uma obra de arte (pintura ou escultura), associandose, assim, à representação verbal de uma imagem visual (WEBB, 2009, p. 1).

${ }^{7}$ Assim como Costigan (2003, p. 54), utilizamos o termo cristão-novo para nos referirmos aos descendentes de judeus da Península Ibérica assim denominados após serem submetidos à conversão ao catolicismo.
} 
obra poética foi produzida na América Portuguesa ${ }^{8}$ e publicada em Portugal, uma vez que "os livros só podiam ser impressos na Metrópole e a sua circulação era, em geral, proibida na Colônia" (VIEIRA, 2017, p. 169). Assim, os textos produzidos em território colonial tinham dois destinos:

ou eram ajuntados em códice e depositados em alguma biblioteca conventual, ou enviados para a Metrópole e publicados em livro. Foi o caso da Prosopopeia, de Bento Teixeira. Escrita em Pernambuco, publicada em Portugal em 1601, a Prosopopeia teve uma edição de quase um milheiro. (VIEIRA, 2017, p. 169-170).

Depreendemos, a partir dos dizeres de Vieira, que a produção literária da América Portuguesa integrava o sistema literário de sua Metrópole, onde as obras eram publicadas, circuladas e lidas, embora tivessem sido produzidas na Colônia. É o caso de Prosopopeia, poema escrito na América Portuguesa e dedicado ao Capitão da Capitania de Pernambuco Jorge de Albuquerque Coelho, mas publicado e lido na Metrópole. Assim, as representações coloniais acompanhavam "o campo literário europeu que, a partir do chamado Renascimento, voltou seus olhos aos preceitos da Retórica antiga" (LEITE, 2019, p. 226). O poema de Teixeira, portanto, é integrante do sistema literário português e associado à imitação de princípios antigos, atuando em prol do bem comum e da manutenção teológico-política da corte portuguesa e da Igreja Católica, devido à representação do arquétipo virtuoso e exemplar de um fidalgo.

De acordo com Nascimento (2016, p. 609), Prosopopeia persiste nos debates literários atuais por ser considerado o primeiro poema da literatura brasileira. A crítica declara ser a obra faltosa de qualidade poética, encarando-a como uma "imitação pouco aprimorada d'Os Lusíadas de Camões" (NASCIMENTO, 2016, p. 609). Certamente, Camões é um dos modelos recuperado para a feitura do poema, mas não é o único, já que Prosopopeia dialoga com o legado do gênero épico, trazendo uma prosopopeia de Proteu, citando divindades mitológicas e, ainda, recuperando lugares-comuns da poesia antiga.

\section{O caráter épico de Prosopopeia}

\footnotetext{
8 Em consonância com Santos (2018), optamos por utilizar a denominação "América Portuguesa" ao invés de "Brasil Colônia", por ser esta expressão vinculada à proposta anacrônica, reproduzida pela historiografia brasileira, de opor diametralmente colônia a metrópole (PRADO JÚNIOR, 2002).
} 
Na tradição greco-latina, a categorização genérica se dava tendo em vista o tipo de verso empregado, mediante um critério métrico, sendo o hexâmetro datílico 9 "considerado o metro épico por excelência" (VASCONCELLOS, 2014, p. 14). De acordo com Hansen (2008, p. 25-26), o verso heroico, apropriado para narrar feitos ilustres, se faz em línguas vulgares por meio da versificação em oitava rima italiana de verso decassílabo com seis rimas alternadas e duas aparelhadas, como é o caso de Prosopopeia. Outras características, além do metro, podem ser destacadas como próprias do gênero épico: a proposição; a invocação; o início do poema in media res; as repetições estruturais; o símile; a êcfrase; o catálogo; e o concilium deorum (LEITE, 2016, p. 19-20). O poema de Bento Teixeira apresenta algumas das características apontadas, como a invocação, mesmo que não seja às Musas, as símiles e a interferência divina nos fatos. Cabe-nos, porém, neste artigo, destacar a êcfrase como figura retórica característica da épica recuperada na produção poética de Teixeira. Em Prosopopeia, a êcfrase está presente, por exemplo, na descrição da casca de Tritão e do recife de Pernambuco, fazendo com que o leitor, ao se deparar com o detalhamento descritivo, se comova e seja mais facilmente persuadido em favor das causas do herói.

Ao tratar das epopeias do século XVI, Hansen (2008, p. 32) destaca uma transformação da "antiga nobreza de armas orgulhosa do sangue, da bruteza da força e da ignorância da latinidade" para uma "nobreza de letras civilizada e erudita, movida por juízo" e subordinada ao rei. Assim, a noção de heroísmo se modifica, pois os próprios valores católicos são, então, considerados heroicos (HANSEN, 2008, p. 32), fazendo com que as epopeias luso-brasileiras incluam os preceitos greco-romanos e adequem o maravilhoso antigo ao seu contexto, alegorizando-o ou substituindo-o pelo cristão ou indígena. Em Prosopopeia, a subordinação à corte (TEIXEIRA. Prosopopeia. 69) e à Igreja (TEIXEIRA. Prosopopeia. 4) são destacadas, bem como a substituição da divindade pagã pela cristã, o que se verifica já na invocação do poema, em que o poeta, ao invés de recorrer às divindades pagãs, invoca o Deus cristão:

As délficas irmãs chamar não quero,

Que tal invocação é vão estudo;

Aquele chamo só, de quem espero

\footnotetext{
${ }^{9}$ Segundo Vasconcellos (2014, p. 13), o hexâmetro datílico é um metro quantitativo baseado numa sucessão de seis unidades ou pés, sendo estes formados por cinco dátilos, uma sílaba longa e duas breves, que podem ser substituídos por espondeus, duas sílabas longas, e por um sexto pé composto somente por duas sílabas, uma longa e outra longa ou breve.
} 
A vida que se espera em fim de tudo.

Ele fará meu verso tão sincero,

Quanto fora sem ele tosco e rudo,

Que por razão negar não deve o menos

Quem deu o mais a míseros terrenos.

(TEIXEIRA. Prosopopeia. 2). ${ }^{10}$

No canto de Proteu, deparamo-nos com outro trecho em que se verifica repúdio à invocação às musas, por serem estas representantes do paganismo:

Não quero no meu canto alguma ajuda

Das nove moradoras de Parnaso,

Nem matéria tão alta quer que aluda

Nada ao essencial deste meu caso.

Porque, dado que a forma se me muda,

Em falar a verdade serei raso,

Que assim convém fazê-lo quem escreve,

Se à justiça quer dar o que se deve.

(TEIXEIRA. Prosopopeia. 24).

Dessa maneira, percebemos que Teixeira, ao recuperar categorias da Antiguidade Clássica em seus escritos, ressignifica-os em função dos preceitos políticos e religiosos de seu momento histórico, o que se constata em outros trechos do poema, como nos versos do canto primeiro: "Que eu canto um Albuquerque soberano, / Da fé, da cara pátria firme muro, / Cujo valor e ser, que o céu lhe inspira, / Pode estancar a lácia e grega lira." (TEIXEIRA. Prosopopeia. 1); ou, ainda, em outros versos do canto 44: "Sei mui certo do fado (prosseguia) / Que trará o lusitano por designo / Escurecer o esforço e valentia / Do braço assírio, grego e do latino." (TEIXEIRA. Prosopopeia. 44), em que o poeta sugere que Jorge de Albuquerque Coelho, porque inspirado pelo céu e sua pátria, ou seja, vinculado às instituições católicas e à corte portuguesa, estaria acima de seus antecessores, que foram cantados em épicas antigas.

\section{A prática letrada da América Portuguesa}

\footnotetext{
10 Perante a dificuldade de se acessar escritos seiscentistas originais e devido à existência de diversos textos retocados para publicação, é preciso selecionar um corpus por edição. Frente a isso, vale ressaltar que, neste artigo, utilizamos a versão de Prosopopeia integrante da obra organizada por Ivan Teixeira Multiclássicos: épicos (2008).
} 
A poesia dos séculos XVI ao XVIII pauta-se na noção de imitação, sendo preciso desconsiderar fatores de originalidade ou subjetividade (MUHANA, 2003, p. 14). Apesar disso, Prosopopeia, redigido entre 1587 e 1592 em Pernambuco e editado, por Antônio Ribeiro, em 1601 em Lisboa foi, por muito tempo, tido como uma "imitação servil de Camões, sem qualidades estéticas apreciáveis" (MUHANA, 2003, p. 14). A condição judaica de Bento Teixeira, assim como sua relação com a comunidade cristã-novista passou a interessar mais à crítica do que as categorias retórico-poéticas empregadas em seus escritos, embora, segundo Muhana (2003, p. 14) em Prosopopeia, nada transpareça concepções judaicas. A crítica brasileira, por sua vez, limitou-se a destacar sua importância histórica, desconsiderando seus aspectos literários e declarando ser Bento Teixeira tão somente um bajulador (MUHANA, 2003, p. 14).

Ao tratar sobre a produção literária da América Portuguesa, Candido (1999, p. 20) afirma que, nos séculos XVI e XVII, havia autores ocasionais cujas obras não foram impressas, pois o Brasil só obteve licença para tipografia em 1808, e ficaram restritas à difusão oral ou manuscrita. Ainda de acordo com o crítico, as letras coloniais são consideradas tão somente manifestações literárias, e não literatura propriamente dita, pois não fazem parte de um sistema literário composto por elementos análogos que as constituíssem como literatura (CANDIDO, 1959, p. 24). Esta, segundo Candido (1959, p. 24), só surgiria no território colonial a partir de 1750, devido ao estabelecimento de uma tradição comum de estilos, temas ou formas, bem como ao distanciamento da produção literária portuguesa, mediante a representação de uma essência de nacionalidade nos escritos. Nesse sentido, restariam às produções literárias anteriores às concepções românticas de nacionalidade, como Prosopopeia, a categoria de manifestação literária. O crítico, nesse viés, refere-se ao poema de Bento Teixeira:

Durante cerca de um século depois da atividade poética de Anchieta, quase não houve no Brasil a produção de escritos onde predominasse a imaginação poética ou ficcional, exceptuando-se coisas tão insignificantes quanto o primeiro poema épico escrito aqui em português, a Prosopopeia (1601), de Bento Teixeira (155?-1600), que só tem o mérito da precedência. (CANDIDO, 1999, p. 20-21).

Percebemos o caráter depreciativo conferido ao poema por Candido, que, em sua obra Iniciação à Literatura Brasileira: resumo para principiantes (1999), expõe citação sobre o poema somente no trecho destacado, evidenciando-o por ser o primeiro poema escrito na América 
Portuguesa, mesmo que sua qualidade fosse questionável. Veríssimo, de maneira semelhante, já antes abordara Prosopopeia por seu valor histórico:

Não tem mérito algum de inspiração, poesia ou forma. Afora a sua importância cronológica de primeira produção literária publicada de um brasileiro, pouquíssimo valor tem. No meio da própria ruim literatura poética portuguesa do tempo - aliás, a só atender à data em que possivelmente foi este poema escrito, a melhor época dessa literatura - não se elevaria este acima da multidão de maus poetas iguais (VERÍSSIMO, 1916, p. 46).

O autor, assim como Candido, desconsidera o aspecto literário do poema, atribuindo a Bento Teixeira a pecha de mau poeta, como foram outros tantos seus contemporâneos, sem no entanto argumentar as razões para este juízo. Já Bosi $(1959$, p. 36) se abstém de classificar o poema qualitativamente, porém ressalta a imitação de Os Lusíadas, de Camões, bem como "o que há de não português (mas não diria: de brasileiro) no poemeto" (BOSI, 1959, p. 36), pois ainda seria precoce atribuir um sentimento nativista aos versos de Teixeira, indicando que o crítico, de maneira semelhante aos anteriores, limitou-se a destacar a importância histórica de Prosopopeia, desconsiderando sua literariedade.

A crítica brasileira dos séculos XIX e XX, como se percebe, trata a produção literária da América Portuguesa como "protoliteratura nacional" (LUZ, 2008, p. 194), por sua suposta falta de qualidade e originalidade, bem como pela dependência da literatura portuguesa. Pretendemos, frente a isso, lê-la como "exemplar de 'práticas letradas' com efeitos próprios, considerando os auditórios do Império Português na virada do século XVI para o XVII" (LUZ, 2008, p. 195), isto é, ler o poema como integrante de sua historicidade e não mediante perspectivas nacionalistas posteriores à sua composição, uma vez que solicitar aos escritores do Pré-romantismo uma postura romântica, de afirmar sua brasilidade, acentuando divergências com a Metrópole, seria anacrônico (LEITE, 2019, p. 219). Quanto a isso, Vieira acrescenta que,

mesmo morando na Colônia, Bento Teixeira, assim como o padre Antônio Vieira e João de Brito Lima, se sentiam tão lusitanos e tão parte da sua vida intelectual como qualquer um dos seus contemporâneos portugueses. $O$ mesmo sentimento que vamos encontrar nos escritores portugueses Diogo do Couto, Bento de Góes, António de Andrade e Fernão Álvares do Oriente. Apesar de escreverem sobre as terras viciosas que o império português vinha dilatando em África e Ásia, todos eles tinham consciência de que eram partes integrantes de um dado sistema intelectual - o português - e que era nesse dado sistema que os seus livros deviam ser impressos 
(como foram) e, principalmente, lidos (como terminaram por ser). (VIEIRA, 2017, p. 171).

Compreendemos, assim, que Bento Teixeira, além de outros escritores que produziam literatura na América Portuguesa, não só integravam o sistema literário português, mediante a publicação de obras em Portugal, mas também se sentiam lusitanos como qualquer outro escritor que habitasse na Metrópole. Esses escritores estavam vinculados às práticas letradas portuguesas, a partir da recuperação de preceitos da Antiguidade Clássica recepcionados na Modernidade, à vista da persuasão da audiência em favor do Império Português. A representação letrada da América Portuguesa, como se verifica, ao invés de sujeita aos moldes românticos que Ihe foram posteriores, se faz mediante a imitação de auctoritates retórico-poéticas, bem como do auctor de um gênero, suas tópicas e estilos (HANSEN, 2006a, p. 24), compondo o sistema literário português. Bento Teixeira, inserido nesse contexto, produz uma épica elogiosa ao Capitão da Capitania de Pernambuco e se utiliza de elementos da Retórica Antiga, reproduzindo a cultura literária do Antigo Regime, de que fazia parte e de acordo com o qual a escrita de textos laudatórios em troca de benesses era comum e representava uma prática de imitação de autores antigos (SOUZA, 2015, p. 375).

\section{Delimitação acerca da ékphrasis}

Em Prosopopeia, Jorge de Albuquerque Coelho e Duarte Coelho de Albuquerque são homenageados de forma que sua retratação imagética produzam efeitos no leitor, que os percebem como retrato da moral (LUZ, 2008, p. 197). A êcfrase, dessa maneira, aparece como figura de suma importância, já que sua vividez descritiva faz com que o leitor crie imagens mentais em relação ao lido e conserve os ensinamentos propostos no poema. Pretendemos, diante disso, analisar trechos ecfrásticos do poema de Bento Teixeira, com o auxílio das instituições retóricas, tendo em vista a recepção desse artifício antigo na Modernidade e sua função na poética seiscentista.

A Retórica é definida por Aristóteles (Rh. 1.1355b) como a capacidade de perceber o que é adequado a determinado caso com o intento de persuadir, residindo as provas de persuasão no caráter moral do orador; no próprio discurso; bem como no modo como este é disposto ao ouvinte (Rh. 1.1356a). Dessa maneira, as figuras retóricas seriam utilizadas de forma que a 
disposição do discurso fosse agradável e alcançasse a audiência, deleitando-a e, concomitantemente, representando-Ihe os modelos de virtude e as causas a serem defendidas. Bento Teixeira, leitor dos preceptistas antigos, recupera princípios clássicos em seus escritos a fim de comover seus ouvintes em favor da Corte portuguesa e da Igreja Católica, fazendo uso da elocução em seus versos para persuadir, a partir da manipulação de artifícios linguísticos diversos, como a êcfrase.

O anônimo autor da Retórica a Herênio (4.51) situa a descrição como o ornamento por meio do qual se expõe, de maneira perspícua, clara e grave, as consequências das ações, podendo-se, assim, suscitar indignação ou misericórdia. De acordo com Rodolpho, (2012, p. 186), a descrição é um efeito de texto que, com a êcfrase, passa a integrá-lo. Como recurso retóricopoético, a êcfrase se integra ao discurso de Teixeira para enumerar as particularidades constitutivas do caráter de Jorge de Albuquerque Coelho, de forma a maravilhar o espectador, persuadindo-o, ao apresentar detalhes com clareza e deleite.

Como consta ainda na Retórica a Herênio (3.33), "com frequência abarcamos a memória de um assunto inteiro com apenas uma marca, em uma só imagem"11, sendo necessário, pois, constituir imagens capazes de aderir por mais tempo à memória (3.37). Já no De Oratore (2.86), Cícero diz ser preciso fazer imagens daquilo que se queira guardar, o que se vincula à fantasia como termo técnico da Retórica, ao demandar "a visualização de imagens ausentes" (RODOLPHO, 2012, p. 127). Segundo Quintiliano (Inst. 6.2.29), fantasia é o meio pelo qual as coisas ausentes são representadas na imaginação com tanta vividez como se as tivéssemos diante do olhar. Logo, a fantasia parece se relacionar aos mecanismos ecfrásticos (RODOLPHO, 2012, p. 141) como um elemento de assimilação visual do que está sendo lido, o que contribui para o convencimento do que se enuncia no discurso.

Segundo Hansen (2006b, p. 89), a êcfrase carrega uma simultaneidade mimética de procedimentos e efeitos necessários de se considerar para não a analisarmos de maneira anacrônica. Além da fantasia, a descrição ecfrástica suscita a enargia ou evidência, figura de pensamento que confere vivacidade à imagem verbal. Quintiliano (Inst. 8.3.61) define a enargia como o procedimento que expõe diante dos olhos, ao tornar claro não só enquanto ornato, mas

11 Rei totius memoriam saepe una nota et imagine simplici conprehendimus. Tradução de Faria e Seabra (2005). 
em função da argumentação de uma causa, pois contribui para que ela pareça mais verdadeira (RODOLPHO, 2012, p. 154). A enargia é adquirida por meio de mecanismos amplificadores, tais como a êcfrase ou a descrição, a fim de garantir credibilidade e ilustrar o discurso verbal, pois o visível comove mais (RODOLPHO, 2012, p. 192). A enargia e a fantasia produzidas por meio da êcfrase aproximam o leitor do fato ou objeto descrito, conferindo-lhe, em conjunto com a vivacidade, maior autonomia e propriedade, de forma que o público assimile o conteúdo da descrição ecfrástica e pressuponha como verdadeiro aquilo que é exposto no enunciado.

A êcfrase, no gênero histórico seiscentista, caracteriza-se por compor a narrativa, sendo formada por "descrições e digressões amplificativas, cujo efeito de verdade é a vivacidade historiográfica" (SINKEVISQUE, 2013, p. 46). A narração, nesse sentido, é acrescida de elementos ecfrásticos que fortalecem o discurso, oferecendo-lhe veracidade. Dessa forma, ao aproximar o leitor do fato narrado, fazendo-o ver a cena retratada, é possível, além de fornecer informações históricas, ensiná-lo o que se pretende, assim como satisfazê-lo na leitura, garantindo maior convencimento. Essa compreensão, ao nosso ver, alcança o poema épico de Bento Teixeira, uma vez que este se constitui por uma narração dos feitos de Jorge de Albuquerque Coelho, em combate com os gentios da costa brasileira, enquanto Donatário da Capitania de Pernambuco, e com os mouros, na batalha de Alcácer-Quibir. Através de seus excertos ecfrásticos, a narrativa alcança feição verídica, de maneira que seus componentes históricos sejam admitidos pelo público como verdadeiros.

Retoricamente, não se opõe descrição à narração, pois aquela integra esta (HANSEN, 2006b, p. 90). Assim, a êcfrase, enquanto procedimento que assimila o verbal ao não-verbal, por se tratar de uma descrição escrita cujos efeitos ultrapassam tal modalidade, pode ser compreendida como um método de amplificação, que combina descrição e narração, comovendo e deleitando o público e, dessa forma, manifestando-se como verossímil (RODOLPHO, 2012, p. 29). A narração e as descrições ecfrásticas funcionam como considerações ornadas a partir de uma proposta didática e deleitosa, a fim de que o discurso apresente, vinculado à instrução, um aspecto aprazível.

\section{A êcfrase em Prosopopeia}


Prosopopeia, composto por noventa e quatro cantos em oitava-rima, é dirigido a Jorge de Albuquerque Coelho e verificamos, em seu prólogo, a proposta de pintar a imagem do fidalgo, o que se evidencia a partir do tópos horaciano (Ars. 361) de que poetas e pintores estariam no mesmo predicamento. O poeta, então, situa seus versos como um esboço, vinculando-os a uma pintura que, antes de ser feita em tela, é rascunhada e solicita a benevolência do homenageado em aceitar a obra que lhe é apresentada. Verificamos a relevância concedida ao aspecto imagético do poema, o qual, sendo composto por trechos ecfrásticos, acaba por resultar em uma grande descrição da imagem de Jorge de Albuquerque Coelho.

Sendo um poema épico, inicia-se com a invocação ao Deus cristão e, em seguida, parte-se para a narração. Primeiramente, discorre-se sobre diversas deidades marinhas, até chegar a Proteu, que tinha o dom da premonição. Faz-se, então, uma descrição do recife de Pernambuco, até que se dá início ao canto de Proteu, que narra post facto os acontecimentos relativos ao heroi. Percebemos, a partir da leitura do poema, o louvor direcionado ao Donatário, cujos atos, por preservarem os valores portugueses e seu ideal expansionista, representam comportamento modelar frente à conduta indígena e moura.

Ao início da narração, apresenta-se uma noite quieta e sossegada, em que as estrelas brilhavam no céu e seus reflexos eram percebidos no mar: "As luzentes estrelas cintilavam, / E no estanhado mar resplandeciam, / Que, dado que no céu fixas estavam, / Estar no licor salso pareciam." (TEIXEIRA. Prosopopeia. 9). O aspecto ecfrástico desses versos pode ser percebido por meio das adjetivações (luzentes; estanhado; fixas; salso) e das referências a brilho (luzentes; cintilavam, estanhado; resplandeciam). Por conta da descrição, é como se acompanhássemos o luzir das estrelas, vendo-as refletidas no mar. A partir disso, principia-se a descrição da chegada de Tritão, na qual consta, ainda, uma êcfrase de sua casca:

Quando ao longo da praia, cuja areia

É de marinhas aves estampada,

E de encrespadas conchas mil se arreia,

Assim de cor azul, como rosada, Do mar cortando a prateada veia, Vinha Tritão em cola duplicada, Não Ihe vi na cabeça casca posta (Como Camões descreve) de lagosta.

Mas uma concha lisa e bem lavrada 
De rica madrepérola trazia,

De fino coral crespo marchetada,

Cujo lavor o natural vencia.

Estava nela ao vivo debuxada

A cruel e espantosa bateria,

Que deu a temerária e cega gente

Aos deuses do céu puro e reluzente.

Um búzio desigual e retorcido

Trazia por trombeta sonorosa,

De pérolas e aljôfar guarnecido,

Com obra mui sutil e curiosa.

Depois do mar azul ter dividido,

Se sentou numa pedra cavernosa,

E com as mãos limpando a cabeleira

Da tortuosa cola fez cadeira.

(TEIXEIRA. Prosopopeia. 10-13).

A descrição nos é oferecida ao olhar, mediante a localização espacial (praia; mar), os adjetivos (encrespadas; lisa; fino; tortuosa), às referências a cor (azul; rosada; prateada) e o encadeamento de ações, responsáveis por conferir maior vividez à narração. Por meio da leitura dos versos e de seu detalhamento descritivo, elaboramos fantasiosamente a imagem de uma praia, repleta de aves marinhas e conchas, de cujo mar advém Tritão. Este porta uma concha dessemelhante à descrita por Camões, bem como um búzio desigual e retorcido, utilizado como trombeta, e, após dividir o mar, senta-se numa pedra, fazendo de sua cauda cadeira. A êcfrase em Prosopopeia emula a mesma imagem presente em Os Lusíadas, diferenciando-se, porém, quando o poeta afirma não ver o que Camões descrevera ${ }^{12}$, mas o que passa a descrever nos próximos versos.

Segundo Nascimento (2016, p. 614), enquanto Camões vincula Tritão ao reino da natureza, Teixeira o traz para o reino da cultura, o que se evidencia pela concha retorcida portada em Os Lusíadas e a concha lisa e lavrada de madrepérola utilizada em Prosopopeia, poema em que a imagem de Tritão é elevada. Ainda em Prosopopeia, na própria concha de Tritão, tem-se uma cena de batalha descrita servindo de base para outra êcfrase, como Homero fizera com o escudo de Aquiles (Ilíada. 18.478-608). Essa cena faz menção aos episódios da Titanomaquia e da Gigantomaquia, narradas por Hesíodo e Apolodoro (NASCIMENTO, 2016, p. 614-615). Dessa

12 “Na cabeça, por gorra, tinha posta / Ũa mui grande casca de lagosta." (CAMÕES. Os Lusíadas. 6.17.7-8). 
maneira, percebemos que Tritão, em Prosopopeia, é luminoso e "funciona como estrutura modelizante duma ekphrasis (a guerra mitológica entre os deuses e os gigantes), com a componente de vividez que esta tradicionalmente comporta" (ALVES, 2012, p. 453-454).

Posteriormente à alusão a Tritão, vê-se a descrição da chegada de diversos deuses: Netuno, com seu tridente, vem em Carro Triunfal; Oceano, de barba branca e cerviz tremente; além de outras deidades marinhas (TEIXEIRA. Prosopopeia. 13-14), até o aparecimento de Proteu, que "Vem numa e noutra forma peregrina, / mudando a natural propriedade." (TEIXEIRA. Prosopopeia. 15). Diante disso, inicia-se a descrição do recife de Pernambuco:

Para a parte do sul, onde a Pequena

Ursa se vê de guardas rodeada, Onde o céu luminoso mais serena Tem sua influição, e temperada; Junto da Nova Lusitânia ordena A natureza, mãe bem atentada, Um porto tão quieto e tão seguro, Que para as curvas naus serve de muro. (TEIXEIRA. Prosopopeia. 17).

Neste trecho, os mecanismos ecfrásticos se vinculam às adjetivações constantes (pequena; serena; temperada; quieto), à referência ao brilho e à luminosidade do céu e ao uso dos verbos no presente (vê; ordena; serve). Assim, a descrição nos é oferecida ao olhar, de forma que avistemos a constelação Ursa Menor, bem como as demais estrelas que a rodeiam, e o litoral pernambucano, cujo recife não permite que navios de grande porte alcancem o território, sendo, portanto, um porto seguro. É possível compreender que a segurança característica da Capitania de Pernambuco se vincula não somente à formação rochosa próxima à costa litorânea, mas à conduta exemplar de seu governante, que resguarda o território das ameaças gentílicas. A descrição do recife prossegue nos cantos seguintes, nos quais verificamos haver uma faixa de pedra ao longo da costa, bem como uma lajem (TEIXEIRA. Prosopopeia. 18-20), por onde chegam os diversos deuses. Dentre estes, está Proteu, que interrompe o silêncio, dando início ao seu canto (TEIXEIRA. Prosopopeia. 21).

No canto de Proteu, trata-se, primeiramente, do esforço empreendido por parte dos irmãos Coelho contra os indígenas na América Portuguesa, na tentativa de convertê-los, de forma 
a estabelecer a fé católica como hegemônica no território colonial (TEIXEIRA. Prosopopeia. 28). Prossegue-se, então, com uma descrição, em que o poeta retrata imageticamente a luta contra os indígenas:

O Princípio de sua primavera

Os bárbaros cruéis e gente austera, Com meio singular, domesticando. E primeiro que a espada lisa e fera Arranquem, com mil meios d'amor brando, Pretenderão tirá-la de seu erro, E senão porão tudo a fogo e ferro.

Os braços vigorosos e constantes Fenderão peitos, abrirão costados, Deixando de mil membros palpitantes Caminhos, arraiais, campos juncados. Cercas soberbas, fortes repugnantes Serão dos novos Martes arrasados, Sem ficar deles todos mais memória Que a qu'eu fazendo vou em esta história.

Quais dois soberbos rios espumosos, Que, de montes altíssimos manando, Em Tétis de meter-se desejosos, Vêm com fúria crescida murmurando; E nas partes que passam furiosos Vêm árvores e troncos arrancando, Tal Jorge d'Albuquerque e o grão Duarte Farão destruição em toda a parte. (TEIXEIRA. Prosopopeia. 30-32).

Esse incidente é retratado por meio de uma êcfrase cujo conteúdo simboliza uma das temáticas principais do poema. O aspecto descritivo se vincula às adjetivações (lisa; brando; vigorosos; repugnantes; espumosos; altíssimos), assim como às referências espaciais (caminhos; campos; rios; montes) e materiais (espada; troncos). As diversas imagens, associadas às ações narrativas, são expostas de forma que consigamos avistar a tentativa de domesticar e catequizar os indígenas. Não sendo todos convertidos, porém, cabe a Jorge de Albuquerque Coelho e a 
Duarte Coelho de Albuquerque praticar a guerra justa ${ }^{13}$, a fim de efetivar a colonização lusa, mediante braços que "Fenderão peitos, abrirão costados, / Deixando de mil membros palpitantes / Caminhos, arraiais, campos juncados.", de maneira que a morte dos nativos e a destruição da natureza apague o que restaria da memória indígena. Essas imagens representam a conduta exemplar dos fidalgos na Capitania de Pernambuco, ao combaterem os indígenas, expurgando seus traços culturais e instituindo o catolicismo e o domínio português.

Outro acontecimento narrado por Proteu é a participação dos irmãos Coelho na batalha de Alcácer-Quibir, na qual enfrentaram os mouros, em Marrocos. O combate se deu em conjunto com o Rei Dom Sebastião, cuja participação é destacada por um trecho ecfrástico:

Entre armas desiguais, entre tambores,

De som confuso, rouco e redobrado, Entre cavalos bravos corredores, Entre a fúria do pó, que é salitrado; Entre sanha, furor, entre clamores, Entre tumulto cego e desmandado, Entre nuvens de setas mauritanas, Andará o Rei das gentes lusitanas. (TEIXEIRA. Prosopopeia. 74).

As imagens associadas à atuação do Rei são descritas de forma que as percebamos no ato de leitura, a partir da pormenorização de especificidades tais quais os utensílios (armas; tambores; setas), as caracterizações (desiguais; bravos; cego) ou ainda a referência aos cavalos, à fúria e ao tumulto, responsáveis por conferir maior vividez à cena, fazendo com que avistemos o Rei em meio às disputas. A participação do Rei no combate simboliza a dedicação da nobreza em relação às conquistas portuguesas. Dá-se, então, início a novo excerto descritivo, no qual se relata a captura de Jorge de Albuquerque Coelho, posteriormente à morte do Rei Dom Sebastião:

Com lágrimas d'amor e de brandura, De seu Senhor querido ali se espede, E que a vida importante e mal segura Assegurasse bem, muito lhe pede. Torna à batalha sanguinosa e dura, O esquadrão rompe dos de Mafamede, Lastima, fere, corta, fende, mata, Decepa, apouca, assola, desbarata.

${ }^{13}$ Frente à insubordinação dos indígenas aos comandos coloniais, declarava-se a denominada guerra justa, por meio da qual os colonizadores empenhavam-se "numa ofensiva militar até submetê-los ao império da lei, fazendo-os viver como vassalos cristãos permanentes" (LANGFUR, 2017, p. 123). 
Com força não domada e alto brio, Em sangue Mouro todo já banhado, Do seu vendo correr um caudal rio, De joelhos se pôs, debilitado.

Ali dando a mortais golpes desvio, De feridas medonhas trespassado, Será cativo, e da proterva gente Manietado enfim mui cruelmente. (TEIXEIRA. Prosopopeia. 79-80).

Neste trecho, percebemos uma descrição do acontecido com Jorge de Albuquerque Coelho, de forma que acompanhemos suas ações, despedindo-se do Rei, retornando à batalha e, então, preso pelos mouros. Os mecanismos ecfrásticos são acionados por meio dos verbos no presente (espede; rompe; pôs), das adjetivações (sanguinosa; caudal; medonhas; proterva) e da progressão de ações, representada pelos versos "Lastima, fere, corta, fende, mata, / Decepa, apouca, assola, desbarata.". A descrição representa a devoção do fidalgo, que, mesmo após a morte do Rei, resiste guerreando e sacrificando-se pelo Império português, sendo até mesmo preso pelos seus inimigos. Posteriormente a esse acontecimento, Jorge, bem como seu irmão, serão resgatados e retornarão ao território brasileiro. Assim, embora derrotados, o poema exulta os esforços lusitanos frente aos feitos dos mouros, de forma que a conduta de Jorge de Albuquerque Coelho se situe como exemplar, sendo inclusive digna de canto e louvor similar aos representados pelos escritos de Virgílio e Homero.

\section{Considerações Finais}

Bento Teixeira, como verificamos, retoma diversos autores e preceitos greco-romanos, incorporando-os à sua escrita e adaptando-os ao panegírico de Jorge de Albuquerque Coelho. Dessa forma, reproduz a prática literária do Antigo Regime, de acordo com a qual se escrevia textos laudatórios em troca de benefícios, e elabora seus versos em retorno à Retórica Antiga, a fim de deleitar e convencer "através do retrato poético dos homenageados, exortando seus auditórios a emulá-los" (FELIPE, 2009, p. 379). A êcfrase está presente em Prosopopeia como figura de elocução que, associada a outros artifícios, insere o poeta nas categorias poéticas de seu tempo, sendo essas relacionadas à imitação de autoridades de determinado gênero. Diante disso, não podemos acatar o posicionamento de que Prosopopeia seria uma imitação mal feita 
de Os Lusíadas, interessante somente por seu aspecto cronológico ou por Bento Teixeira ser um cristão-novo, sendo adequado, nesse sentido, fazer uma leitura retórico-poética do poema, e não uma análise baseada em perspectivas ulteriores à sua feitura, a fim de que seus atributos literários sejam alcançados.

Além das referências mitológicas, as figuras de estilo integram a elocutio do poema. Destacamos, neste artigo, a êcfrase dentre as figuras elocutivas, sendo ela não simplesmente um ornamento, conforme compreendido em seu sentido atual, mas um recurso argumentativo, por meio do qual se aproxima os escritos da audiência, de forma que esta, ao se deparar com a vividez descritiva, formule mentalmente a cena descrita, mantendo-a na memória. A imagem dos fidalgos, produzida nos versos de Bento Teixeira, pode ser ressaltada por meio dos trechos ecfrásticos, que comovem e fazem com que o leitor fantasiosamente estabeleça imagens mentais em relação ao que lê e, dessa maneira, seja convencido pelo discurso, preservando na memória os fatos como foram transmitidos pela narrativa.

\section{Referências Bibliográficas}

ALVES, Hélio J. S. A casca de Tritão: teoria poética na crítica quinhentista a Os Lusíadas: a leitura "brasileira" de Bento Teixeira. In: REUNIÃO INTERNACIONAL DE CAMONISTAS, 6., 2012, Coimbra. Actas da VI Reunião Internacional de Camonistas. Coimbra: Imprensa da UC, 2012. p. 449-458. Disponível em: https://digitalis-dsp.uc.pt/jspui/bitstream/10316.2/31199/1/34Actas_da_VI_reuniao_internacional_de_camonistas.pdf?ln=pt-pt. Acesso em 22 jun 2020.

ARISTÓTELES. Retórica. Tradução e notas de Manuel Alexandre Júnior, Paulo Farmhouse Alberto e Abel do Nascimento Pena. Lisboa: Imprensa Nacional - Casa da Moeda, 1998.

BAKHTIN, Mikhail. Problemas da poética de Dostoievski. Tradução de Paulo Bezerra. 5a. ed. Rio de Janeiro: Forense, 2013.

BAKOGIANNI, Anastasia. O que há de tão 'clássico' na recepção dos clássicos? Teorias, metodologias e perspectivas futuras. In: Codex, Rio de Janeiro, v. 4, n. 1, p. 114-131, 2016. Disponível em: https://revistas.ufrj.br/index.php/CODEX/article/view/3341/2612. Acesso em 22 jun 2020.

BATSTONE, William. Provocation: the point of Reception Theory. In: MARTINDALE, Charles; THOMAS, Richard F (Org.). Classics and the Uses of Reception. Oxford: Blackwell, 2008, p. 14-20. BOSI, Alfredo. História concisa da Literatura Brasileira. 50a. ed. São Paulo: Cultrix, 2015 [1970]. 
CAMÕES, Luís Vaz de. Os Lusíadas. Porto Alegre: L\&PM, 2008.

CANDIDO, Antonio. Formação da literatura brasileira: momentos decisivos. 6a. ed. Belo Horizonte: Itatiaia, 1981 [1959].

CANDIDO, Antonio. Iniciação à Literatura Brasileira: Resumo para principiantes. 3a. ed. São Paulo: Humanitas, 1999.

CÍCERO. Sobre o orador. In: SCATOLIN, Adriano. A invenção no Do Orador de Cícero: um estudo à luz de Ad Familiares I, 9, 23. São Paulo, 2009. 313f. Tese (Doutorado em Letras Clássicas) Programa de Pós-Graduação em Letras Clássicas, Departamento de Letras Clássicas e Vernáculas, Faculdade de Filosofia, Letras e Ciências Humanas, Universidade de São Paulo. p. 148-308.

[CÍCERO]. Retórica a Herênio. Tradução de Ana Paula Celestino Faria e Adriana Seabra. São Paulo: Hedra, 2005.

COSTIGAN, Lúcia Helena. Empreendimento e resistência do cristão-novo face à política de Felipe II: o processo inquisitorial de Bento Teixeira. In: Colonial Latin American Review, v. 12, n. 1, p. 37-61, 2003.

FELIPE, Cleber Vinicius do Amaral. Mitologia e emulação poética em Prosopopeia: harmonização entre elementos potencialmente conflitantes. In: História \& Perspectivas, Uberlândia, v. 22, n. 41, p. 353-382, jul-dez 2009. Disponível em: http://www.seer.ufu.br/index.php/historiaperspectivas/article/view/19246/10374. Acesso em 22 jun 2020.

GADAMER, Hans-Georg. Truth and Method. 2nd. ed. New York: Continuum. 1965 [1960].

HANSEN, João Adolfo. Letras coloniais e historiografia literária. In: Matraga, Rio de Janeiro, v. 18, p. 13-44, 2006a. Disponível em: http://www.pgletras.uerj.br/matraga/matraga18/matraga18a01.pdf. Acesso em 22 jun 2020.

. Categorias epidíticas da ekphrasis. In: Revista Usp, São Paulo, n. 71, p. 85-105, set-nov 2006b. Disponível em: http://www.revistas.usp.br/revusp/article/view/13554/15372. Acesso em 22 jun 2020.

. Introdução: notas sobre o gênero épico. In: TEIXEIRA, Ivan (Org.). Multiclássicos: épicos. São Paulo: Edusp - Imprensa Oficial do Estado de São Paulo, 2008, p. 15-91.

. Lugar-comum. In: MUHANA, Adma; LAUDANNA, Mayra; BAGOLIN, Luiz Armando (Org.). Retórica. São Paulo: Annablume, 2012, p. 159-177.

HOMERO. Ilíada. Tradução de Carlos Alberto Nunes. Rio de Janeiro: Nova Fronteira, 2011.

HORACIO. Arte poética. Tradução de Raul Miguel Rosado Fernandes. Lisboa: Editorial Inquérito, 1984. 
ISER, Wolfgang. The Act of Reading: A Theory of Aesthetic Response. Baltimore: The Johns Hopkins University, 1978.

JAUSS, Hans Robert. Towards an Aesthetic of Reception. Translated by Timothy Bahti. Minneapolis: University of Minnesota, 1982.

KRISTEVA, Julia. Le mot, le dialogue et le roman. In: Critique, Paris, v. 23, p. 438-465, 1967.

LANGFUR, Hal. Canibalismo e a legitimidade da guerra justa na época da Independência. Tradução de Sergio Lamarão. In: Revista Brasileira de História, São Paulo, v. 37, n. 75, p. 119-143, 2017. Disponível em: https://www.scielo.br/pdf/rbh/v37n75/1806-9347-rbh-2017v37n75-05.pdf. Acesso em 22 jun 2020.

LEITE, Leni Ribeiro. A poesia épica. In: LEITE, Leni Ribeiro: Épica II: Ovídio, Lucano e Estácio. Campinas: Editora da Unicamp, 2016, p. 13-30.

- Leitura e literatura no Brasil Colônia: esquecimentos e apagamentos dos séculos XVI ao

XVIII. In: Contexto, Vitória, n. 36, p. 210-238, 2019. Disponível em: https://periodicos.ufes.br/contexto/article/view/24561. Acesso em 22 jun 2020.

LUZ, Guilherme Amaral. O Canto de Proteu ou a corte na colônia em Prosopopeia (1601), de Bento Teixeira. In: Tempo, Niterói, v. 13, n. 25, p. 193-215, 2008 . Disponível em: https://www.scielo.br/pdf/tem/v13n25/a09v1325.pdf. Acesso em 22 jun 2020.

MARTINDALE, Charles. Redeeming the text: Latin poetry and the hermeneutics of reception. Cambridge: University Press, 1993.

MUHANA, Adma Fadul. O Prosopopeia de Bento Teixeira: epopéia de derrotas. In: ENCONTRO BRASILEIRO DE PROFESSORES DE LITERATURA PORTUGUESA, 19., 2003, Curitiba. Anais do XIX Encontro Brasileiro de Professores de Literatura Portuguesa - Imaginário: o não-espaço do real. Curitiba: Universidade Federal do Paraná, 2003. p. 14-19.

NASCIMENTO, Ana Paula Gomes do. Bento Teixeira e o legado da poesia épica: reflexões sobre um "poemeto épico" do século XVI luso-americano. In: ENCONTRO ABRALIC, 15., 2017, Rio de Janeiro. Anais eletrônicos do XV Encontro ABRALIC. Rio de Janeiro, 2017. p. 609-616. Disponível em: http://www.abralic.org.br/anais/arquivos/2016_1491258280.pdf. Acesso em 22 jun 2020.

PAES, Maria Paula Dias Couto. A sociedade do corpo místico: a formação do império e a fundação da América Portuguesa. Belo Horizonte, 2006. 288 f. Tese (Doutorado em História) - Faculdade de Filosofia e Ciências Humanas, Universidade Federal de Minas Gerais.

PRADO JÚNIOR, Caio. Formação do Brasil contemporâneo: Colônia. 2a. ed. v. 3. Rio de Janeiro: Nova Aguilar, 2002.

QUINTILIANO, Marcos Fábio. Instituição Oratória. Tradução, apresentação e notas de Bruno Fregni Bassetto. Campinas: Editora da Unicamp, 2015. 
RIBEIRO, Eneida Beraldi. Bento Teixeira: Inquisição e Sociedade Colonial. In: WebMosaica, Porto Alegre, v. 4, n. 1, p. 50-56, $2012 . \quad$ Disponível em: https://seer.ufrgs.br/webmosaica/article/view/31820/19875. Acesso em 22 jun 2020.

RODOLPHO, Melina. Imagem verbal - ocorrências da êcfrase na Eneida. In: MARTINS, Paulo; CAIRUS, Henrique Fortuna; OLIVA NETO, João Angelo (Org.). Algumas visões da antiguidade. Rio de Janeiro: 7Letras/Faperj, 2011, p. 188-210.

RODOLPHO, Melina. êcfrase e Evidência nas Letras Latinas: Doutrina e Práxis. São Paulo: Humanitas, 2012.

SANTOS, Fernanda Cristina da Encarnação dos. A retórica da alteridade na "Relação da Missão da Serra da Ibiapaba", do padre Antônio Vieira. Vitória, 2018. 140 f. Tese (Doutorado em Letras) - Centro de Ciências Humanas e Naturais, Universidade Federal do Espírito Santo.

SINKEVISQUE, Eduardo. Usos da êcfrase no gênero histórico seiscentista. In: História da Historiografia, Ouro Preto, n. 12, p. 45-62, 2013. Disponível em: https://www.historiadahistoriografia.com.br/revista/article/view/607/379. Acesso em 22 jun 2020.

SOUZA, Juarlyson Jhones Santos de. O Colégio Jesuíta da Bahia e a formação de círculos letrados nas duas últimas décadas do século XVI. Os casos de Bento Teixeira e Bartolomeu Fragoso. In: Territórios \& Fronteiras, Cuiabá, v. 8, n. 2, p. 365-384, 2015. Disponível em: http://www.ppghis.com/territorios\&fronteiras/index.php/v03n02/article/view/397/pdf. Acesso em 22 jun 2020.

TEIXEIRA, Bento. Prosopopeia. In: TEIXEIRA, Ivan (Org.). Multiclássicos: épicos. São Paulo: Edusp - Imprensa Oficial do Estado de São Paulo, 2008, p. 119-154.

TEIXEIRA, Ivan. Hermenêutica, Retórica e Poética nas letras da América Portuguesa. In: Revista USP, São Paulo, n. 57, p. 138-159, 2003. Disponível em: http://www.revistas.usp.br/revusp/article/view/33838/36571. Acesso em 22 jun 2020.

THEON, Aelius. The Exercises of Aelius Theon. In: KENNEDY, George Alexander. Progymnasmata: Greak Textbooks of Prose Composition and Rhetoric. Translated by George Alexander. Atlanta: Society of Biblical Literature, 2003, p. 1-72.

VASCONCELLOS, Paulo Sérgio de. Definindo épica. In: VASCONCELLOS, Paulo Sérgio de. Épica I: Ênio e Virgílio. Campinas: Editora da Unicamp, 2014, p. 11-29.

VERÍSSIMO, José. História da Literatura Brasileira. Brasília: EdUnb, 1981.

VIEIRA, Anco Márcio Tenório. O tempo e o espaço das "manifestações literárias". In: Investigações, Recife, v. 30, n. 1, p. 157-177, 2017.

WEBB, Ruth. Ekphrasis, Imagination and Persuasion in Ancient Rhetorical Theory and Practice. Burlington: Ashgate, 2009. 